\title{
Redes de cooperação com foco em inovação: um estudo exploratório
}

\section{Enterprise networks focused on innovation: a exploratory study}

\author{
José Roberto Tálamo ${ }^{1}$ \\ Marly Monteiro de Carvalho
}

\begin{abstract}
Resumo: O objetivo deste estudo é levantar os fatores motivadores e críticos ao sucesso da estruturação de redes de cooperação com foco em inovação. Para tal, desenvolveu-se um estudo exploratório em três redes de cooperação intensivas em tecnologia, que aglutinam ao todo 15 empresas. Os resultados obtidos demonstraram que a estruturação na forma de redes de cooperação traz resultados efetivos às empresas integrantes, dotando-as de competitividade e flexibilidade frente aos desafios de mercado. Porém, exige amadurecimento tanto da rede de cooperação quando dos próprios empresários que a integram, a fim superarem suas próprias dificuldades culturais, evitando barreiras ao aprendizado e ao perfil sinérgico.
\end{abstract}

Palavras-chave: Rede de cooperação. Confiança. Fluxo de informações.

\begin{abstract}
The objective of this study is to identify the critical and motivational factors for the success of cooperation networks focused on innovation. Therefore, an exploratory study was carried out in three intensive technology cooperation networks that consist of fifteen companies. The findings demonstrated that the cooperation network structure provides the participant companies with effective results by improving competitiveness and flexibility meeting market challenges. However, it demands maturity of the cooperation networks and entrepreneurs who integrate them in order to overcome cultural difficulties preventing barriers to learning and to the synergistic profile.
\end{abstract}

Keywords: Network. Trust. Information flow.

\section{Introdução}

A crescente concorrência entre as empresas e a velocidade das mudanças no ambiente competitivo tem atuado como catalisador na geração de inovações tecnológicas. Com isto, produtos e processos produtivos tornam-se crescentemente complexos, extrapolando a esfera de conhecimento de uma empresa isolada, impossibilitando o domínio de todas as tecnologias envolvidas no desenvolvimento de novos produtos, além de aumentar a pressão financeira sobre seus resultados. A atividade inovadora, por sua própria natureza, é um processo social e coletivo, no qual o aprendizado se dá por meio das interações, sendo que, quanto mais complexo for o aprendizado, maior será a necessidade de interação e complementaridade (CARVALHO, 2009). Desta forma, esse novo ambiente de inovação aberta depende das comunidades e redes de inovação, que devem criar valor e trazer benefícios coletivos, apesar de ser um ambiente sujeito a incertezas, dado que nem sempre quem gera a inovação é quem capta valor nesse ambiente (CHESBROUGH; APPLEYARD, 2007).
A fim de enfrentar o ambiente de incertezas, as empresas adotaram programas de desintegração vertical, horizontalização, focalização, parcerias e terceirização (AMATO NETO, 2000), que redundaram na criação de várias modalidades de agrupamentos empresariais, tais como: Alianças Estratégicas, Arranjos Produtivos Locais, Cadeias Globais de Commodities ou Manufatura, Condomínio Industrial, várias modalidades de Consórcios, Empresa Estendida, Empresa Virtual, Franquia, Holding, Joint Venture, Outsorcing, diversas modalidades de Rede de Cooperação Empresarial, Terceirização, Subcontratação e as Unidades Virtuais de Negócios (TÁLAMO, 2008).

Por outro lado, o lócus da inovação deve estar em um ambiente de experimentação em rede, não apenas restrita à cadeia produtiva, mas sim em redes de competência (PRAHALAD; RAMASWAMY, 2004).

Neste contexto, o artigo busca levantar os fatores motivadores e críticos ao sucesso da estruturação de redes de cooperação com foco em inovação. A metodológica aplicada foi o estudo exploratório aplicado a três diferentes redes de cooperação.

\footnotetext{
${ }^{1}$ Departamento de Engenharia de Gestão, Universidade Federal do ABC - UFABC, E-mail: roberto.talamo@ufabc.edu.br

${ }^{2}$ Departamento de Engenharia de Produção, Escola Politécnica da Universidade de São Paulo - USP, E-mail: marlymc@usp.br 


\section{Revisão da literatura}

O estudo está estruturado em 3 blocos conceituais que serão explorados nesta seção, quais sejam: fatores motivadores, formação da rede e impactos resultantes da rede (Figura 1 ).

A montante, estão os fatores motivadores, ou seja, forças que movem instituições isoladas e se agruparem sob a forma de redes de cooperação.

A formação da rede envolve aspectos estruturais e de gestão. Dentre os aspectos estruturais destacam-se a configuração da rede, os papéis desempenhados pelos integrantes, o tipo de governança estabelecida e os níveis de interação envolvidos entre os atores. Quanto aos aspectos de gestão da rede, destacam-se as ferramentas de gestão, a organização da rotina de trabalho da rede, a infraestrutura estabelecida entre os integrantes e os recursos de apoio à gestão.

A jusante, estão os impactos da formação da rede, que envolvem as ações de cooperação desenvolvidas pela rede e o impacto observado nos resultados das empresas participantes.

\subsection{Configurações das redes}

Ao se estruturarem sob a forma de redes de cooperação, as empresas podem estabelecer agrupamentos baseados na hierarquia, na qual prevalece a forma de governança entre os integrantes, ou na formalização, classificadas conforme a ocorrência de instrumentos legais de regulação.

Storper e Harrison (1991) classificam as redes estabelecidas, conforme o grau de hierarquia, em quatro formas básicas. Redes Simétricas ou Flexíveis: igualitárias na relação entre os integrantes, sem qualquer espécie de hierarquia entre eles. Redes Levemente Assimétricas com Coordenação: apresentam leve grau de hierarquia devido à relativa influência da empresa coordenadora, porém limitada e não determinante da sobrevivência das empresas participantes do sistema. Redes Assimétricas com Empresa Líder: apresentam forte assimetria hierárquica entre a empresa líder e os integrantes, cuja sobrevivência condiciona-se à estratégia da líder. Redes Hierárquicas: estruturadas por meio da plena formalidade entre a empresa líder e as demais integrantes.

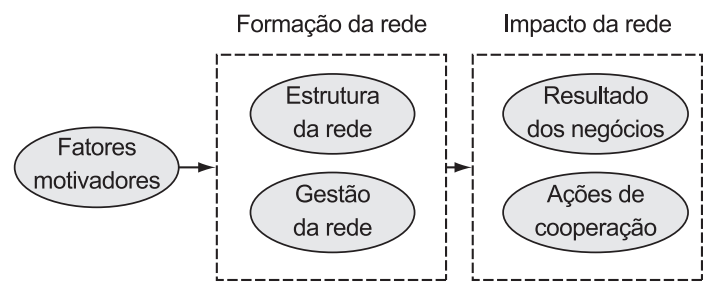

Figura 1. Quadro conceitual.
Fusco et al. (2005) estabelece 5 formas de organização baseadas no grau de formalização legal estabelecido entre os integrantes.

- Redes Sociais Simétricas: não há instrumentos legais, tal como um contrato, que vincule os integrantes; um integrante tem liberdade para aderir ou desligar-se da rede a qualquer momento. Todos têm o mesmo poder decisório, formando um agrupamento de caráter essencialmente social;

- Redes Sociais Assimétricas: os integrantes regulam sua parceria por meio de contratos que regulam apenas a troca de bens e serviços, mas ainda há a liberdade de um integrante aderir ou desligar-se da rede a qualquer momento;

- Redes Burocráticas Simétricas: são reguladas por contratos formais com cláusulas que estabelecem relações, direitos, obrigações, formalização de trocas e acordos e a proteção dos direitos individuais dos integrantes;

- Redes Burocráticas Assimétricas: há instrumentos legais voltados ao alinhamento estratégico dos integrantes aos interesses do agente gestor, com estabelecimento de direitos, transferência de conhecimento e padronização de serviços e informações entre os integrantes;

- Redes Proprietárias Simétricas: as empresas integrantes estabelecem uma nova empresa como forma de equilíbrio de conhecimentos e capitais. Os acordos e direitos à propriedade dos integrantes são estabelecidos por contratos formais e cláusulas específicas; e

- Redes Proprietárias Assimétricas: neste caso há o aspecto "risco" envolvido, adicionalmente às características presentes nas redes Proprietárias Simétricas. Neste tipo de agrupamento, há um investidor e a empresa como parceiros de risco.

Permeando estas configurações e formas, Carvalho, Serra e Laurindo (2003) destacam as ações conjuntas (join actions) entre as empresas integrantes de uma rede, de acordo com o tipo de cooperação existente entre os integrantes, estabelecendo:

- Cooperação horizontal: ocorre entre duas ou mais empresas competidoras entre si, dentro de uma rede já estruturada. Por sua própria configuração, ocorre com mais frequência entre as empresas de uma Rede Simétrica; e

- Cooperação vertical: ocorre entre empresas integrantes de uma cadeia vertical. Neste caso, também por sua configuração, é mais frequente dentro das Redes Hierárquicas. 
No contexto das ações conjuntas ocorrerá o fluxo das informações, de acordo com os laços estabelecidos pelos integrantes, o que definirá o equilíbrio e o grau de aprendizado entre os integrantes, conforme detalhado a seguir.

\subsection{Estabelecimento de laços entre os integrantes das redes}

Matheus e Silva (2006) argumentam que os integrantes de uma rede de cooperação estabelecem laços de conexão entre si, responsáveis pela forma e configuração da rede, ou seja, formadores de sua taxonomia; além disso, esses laços estabelecidos são fundamentais ao fluxo do conhecimento e aprendizado ao longo da rede de cooperação. Granovetter (1985) definiu estes laços como sendo: ausentes, ou seja, lacunas de comunicação e barreiras à expansão do conhecimento, portanto indesejáveis por não agregarem qualquer benefício à rede empresarial; fortes, baseados em alta dose emocional, forte confiança recíproca e longo tempo de formação. É o que Lazzarini, Chaddad e Neves (2000) citam como característicos das empresas familiares. Apesar de proporcionarem confiança mútua, fundamental ao sucesso da rede de cooperação, podem "engessar" sua estrutura, comprometendo sua evolução e a aquisição do conhecimento; fracos: fundamentais à circulação de informações não redundantes. Conforme Granovetter (1985), eles geram conexões com ampla troca de novas informações e são adequados ao preenchimento dos "buracos estruturais", ou seja, lacunas de conhecimento, indicando oportunidades de intermediação (brokerage).

A maior ou menor intensidade dos laços fracos, o balanceamento adequado na intensidade dos laços fortes e a identificação dos laços ausentes irão definir os fatores de sucesso ou insucesso de uma rede social.

Borgatti e Croos (2003) estabelecem uma classificação adicional aos laços de conexão, conforme sua natureza, denominando-os:

- Associativistas: os integrantes participam de eventos comuns, tais como seminários, congressos, convenções, associações, etc;

- Biológicos: em que prevalecem graus de parentesco, como entre pai e filho;

- Formais: estabelecidos por uma hierarquia empresarial ou social mais rígida;

- Individuais: em que predomina a amizade entre os atores;

- Interativos: resultantes da aproximação voluntária dos integrantes, motivada por interesses comuns e convergentes;

- Transacionais: responsáveis pelas transferências de bens ou recursos materiais; e
- Transferenciais: responsáveis pelas transferências de bens intangíveis, tais como serviços ou informações.

As classificações de Borgatti e Croos (2003) e de Granovetter (1985) se justapõem e auxiliam na definição da natureza do aprendizado das redes. A qualidade desses laços é fundamental à obtenção de informações estratégicas, proporcionando aprendizado, vantagens competitivas e potencialização das redes nas quais os integrantes estão inseridos.

\subsection{Aprendizagem e conhecimento}

Uma rede de cooperação empresarial é, fundamentalmente, o agrupamento de empresas que se identificam em seus interesses fundamentais. Os laços estabelecidos entre os integrantes conectam seus interesses individuais, estabelecendo uma vinculação social baseada na troca de conhecimentos. Onyx e Bullen (2000) afirmam que empresas e pessoas, ao se agruparem sob a orientação de normas e condutas sociais, objetivando o benefício comum, estabelecem uma organização social, gerando o capital social da rede de cooperação entre empresas. Conforme Malafaia et al. (2007), a ocorrência desse capital social estimula o surgimento de relações de confiança e colaboração, levando a um ambiente de estímulo ao desenvolvimento conjunto e coletividade.

Os laços estabelecidos pelos integrantes definirão o grau de interação e aprendizado da rede de cooperação, interferindo diretamente na sua evolução e no manuseio do seu conhecimento. A troca de conhecimentos e aprendizados proporcionada pelos laços de conexão estabelecerá a evolução tecnológica dos integrantes, pois a gestão da tecnologia acaba redundando na gestão do conhecimento, conforme estabelecido por Karlsson (2003). Conforme o autor, há dois tipos genéricos de tecnologia: a tecnologia vertical e a horizontal. A tecnologia vertical envolve a pesquisa pura, em áreas muito especializadas, em geral, distante dos processos de gestão das redes. É a própria ciência, conforme a definição de Stokes (2005).

A tecnologia horizontal, por outro lado, engloba processos de gestão relacionados a produtos e processos e cria a necessidade de perspectivas mais amplas, que resultam na divisão de tarefas entre participantes de redes sociais. Karlsson (2003) argumenta que compreender a robustez, flexibilidade, habilidade de gerar mudanças e rapidez de resposta às mudanças ambientais implica em dominar a dinâmica destas interações, fato essencial à análise do conhecimento dentro das redes de cooperação.

A combinação dos diferentes laços de conexão entre atores definirá formas de aprendizagem e de interação, que resultam em três categorias de redes, 
conforme Belussi e Arcangeli (1998), e ilustrado na Figura 2. Sob este prisma, as redes classificam-se em:

- Redes Estacionárias: restringem a divisão do trabalho aos integrantes, estabelecendo relações estáticas que bloqueiam novos conhecimentos e competências coletivas. Esta situação ocorre predominantemente sob laços fortes, fruto da alta confiança entre os atores, em decorrência de laços classificados predominantemente como biológicos, individuais ou formais, que podem "engessar" o fluxo de informação. Também podem ocorrer os laços ausentes, como resultado da desmotivação ou formalidade entre os atores integrantes da rede. Esta configuração dificulta a identificação dos buracos estruturais como oportunidades de ganhos e vantagens competitivas aos próprios integrantes;

- Redes Retráteis - reversíveis: as relações entre os atores são mais frequentes e dinâmicas, capazes de incorporarem novos conhecimentos, o que facilita a adaptação às flutuações de demanda. Nesta configuração, podem ocorrer laços fortes ou ausentes, mas já se observa a ocorrência de laços fracos, resultantes de laços classificados como associativistas e interativos. Há favorecimento à interação entre diferentes redes e geração de aprendizado adaptativo, fruto da conexão com agentes externos; e

- Redes Evolucionárias: caracterizadas por intenso aprendizado e formação de competências coletivas. Os integrantes são capazes de identificar suas competências internas (core competences) e de se combinarem em termos de aumento da escala aparente de geração de produtos. Nesta situação podem ocorrer laços ausentes ou fortes, mas predominam os laços fracos, classificados como transacionais e transferenciais, fruto da intensa transferência de bens tangíveis e intangíveis sob a forma de materiais, recursos, serviços e informações. Desse modo, a rede social apresenta evolução e os buracos estruturais são identificados e transpostos com mais eficiência, devido às conexões estabelecidas pelos laços fracos.

Em um grupo de empresas integrantes de uma rede, sempre ocorrerá o aspecto "competição" em paralelo ao fator "cooperação", fruto dos próprios laços de conexão dos integrantes. Caberá a estes, o equilíbrio entre as forças de cooperação e competição, determinantes ao sucesso do processo de aprendizagem e evolução, gerador de vantagens competitivas.

Dentro deste contexto de aprendizagem e evolução, Loebbecke e Van Fenema (1998) definem as três forças que atuam sobre o equilíbrio cooperação-competição:

- Sinergia: é o potencial de adição de valor proporcionado pela troca de informações entre as partes envolvidas. Tanto o emissor quanto o receptor da informação evoluem;

- Nivelamento: é a capacidade de aumentar o valor do receptor da informação, explorando o conhecimento compartilhado e extrapolando a relação de cooperação. Há tendência para o equilíbrio entre as partes; e

- Impacto reverso-negativo: caracterizado pela redução de valor da parte emissora da informação, devido ao uso da informação pela parte receptora. É um inibidor ao equilíbrio cooperação-competição.

A Tabela 1 sintetiza a relação entre laços, taxonomia da rede e forças atuantes quanto ao aprendizado e interação.

O fator determinante do sucesso destas redes será a "confiança", conforme veremos a seguir.

\subsection{Confiança versus oportunismo}

Uma rede de cooperação empresarial tem maior probabilidade de sucesso quando é estruturada por

Tabela 1. Relação entre laços de atores e taxonomias de redes.

\begin{tabular}{|c|c|c|c|c|}
\hline $\begin{array}{l}\text { Tipos de laços } \\
\text { entre os atores }\end{array}$ & $\begin{array}{c}\text { Classificação dos laços } \\
\text { predominantes }\end{array}$ & $\begin{array}{c}\text { Capacidade de } \\
\text { identificação dos } \\
\text { buracos estruturais }\end{array}$ & $\begin{array}{l}\text { Taxonomia da } \\
\text { rede }\end{array}$ & $\begin{array}{l}\text { Força atuante } \\
\text { mais provável }\end{array}$ \\
\hline Ausentes e/ou fortes & $\begin{array}{c}\text { Biológicos, } \\
\text { Individuais e Formais }\end{array}$ & Baixa & Estacionária & $\begin{array}{c}\text { Impacto } \\
\text { reverso negativo }\end{array}$ \\
\hline $\begin{array}{l}\text { Ausentes, fortes e alguma } \\
\text { ocorrência de laços fracos }\end{array}$ & $\begin{array}{l}\text { Associativistas e } \\
\text { Interativos }\end{array}$ & Média & Retrátil-reversível & Nivelamento \\
\hline $\begin{array}{l}\text { Baixa incidência de laços } \\
\text { fortes e/ou ausentes e alta } \\
\text { incidência de laços fracos }\end{array}$ & $\begin{array}{l}\text { Transacionais e } \\
\text { Transferenciais }\end{array}$ & Alta & Evolucionária & Sinergia \\
\hline
\end{tabular}




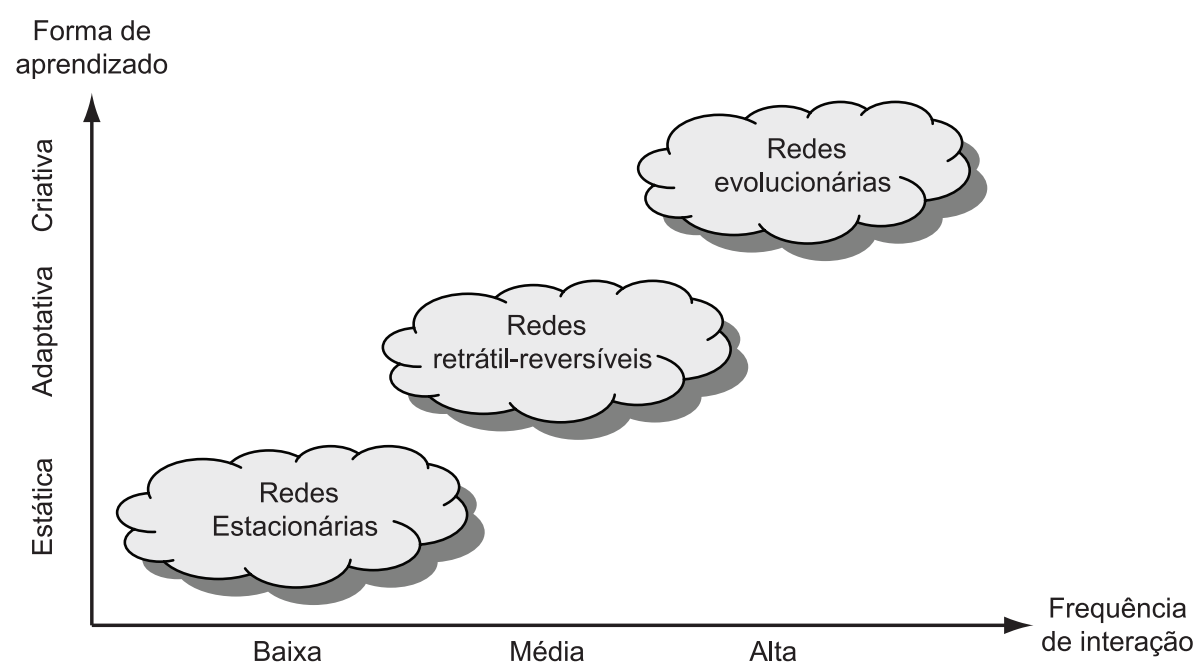

Figura 2. Tipologia de redes conforme Belussi e Arcangeli (1998).

meio de caráter motivacional e em torno de objetivos claros e comuns.

Isto significa que o sucesso de uma rede de cooperação não depende do caráter volitivo, ou seja, da formação estabelecida por voluntários em resposta a uma chamada; o sucesso ocorre por meio do caráter motivacional, com a aproximação espontânea e automotivada de seus integrantes, conforme definido por Tálamo (2008). Ao mesmo tempo, cada rede de cooperação apresenta características peculiares que exigem ações específicas; por exemplo, empresas cuja estratégia corporativa está apoiada no fortalecimento do capital intelectual não devem buscar agrupamento com empresas que privilegiam a subcontratação.

Os integrantes devem ser motivados pelo reconhecimento de que seus interesses individuais podem ser compartilhados a fim de proporcionar ganhos comuns, viabilizados pela cultura da participação e troca, de forma a construir o capital social da rede empresarial, responsável pelo estabelecimento das relações de confiança e colaboração, de acordo com Malafaia et al. (2007). Conforme os autores, o estabelecimento do capital social, gerado pelo compartilhamento de interesses, é a base para o estabelecimento de relações de confiança, fundamental ao desenvolvimento conjunto. Ainda segundo Malafaia et al. (2007), a confiança é, ao mesmo tempo, barreira e caminho; a construção da confiança mútua é a grande barreira à formação de redes de cooperação, ao mesmo tempo em que é fundamental ao sucesso dessa rede de cooperação.

É a presença da confiança dentro de uma rede de cooperação que estabelece e molda a intensidade adequada dos laços estratégicos à sua evolução e sucesso. Olave e Amato Neto (2001) associam a confiança e ética aos laços familiares, ou seja, fortes e de classificação biológica; entretanto, eles podem ser confiáveis em termos de construção da confiança, mas podem levar ao "engessamento" da rede ao longo do tempo, em função de sua intensidade inadequada, estabelecendo perfil estacionário, ausência de pontes e falha na identificação dos buracos estruturais. Porém, Gulati (1995) afirma que a dificuldade de construção do fator confiança é um item crítico comum a todas as redes empresariais, isto é, o temor ao comportamento oportunista é intrínseco às redes empresariais. Enquanto os laços fortes favorecem o estabelecimento da confiança, mas podem moldar o perfil estacionário, os laços fracos preenchem buracos estruturais, porém são instáveis em termos de confiança. A adequada intensidade entre esses laços extremos deve ser estabelecida pelos integrantes da rede de cooperação, junto à construção do fator confiança.

Os integrantes da rede de cooperação devem estabelecer meios ou instrumentos legais que previnam a ocorrência de falhas na construção da confiança, de modo a prevenir a ocorrência do temor ao comportamento oportunista entre os integrantes. Dentre os fatos que comprometem a construção da confiança dentro da rede de cooperação, Gulati (1995) destaca as parcerias empresariais de longo prazo e a quantidade excessiva de alianças empresariais, que podem limitar a percepção de comportamentos oportunistas, tornando a empresa vulnerável a parcerias não confiáveis. Ainda conforme Gulati (1995), quando o comportamento oportunista é identificado no compartilhamento de duas ou mais empresas, os laços de cooperação se desfazem imediatamente e dificilmente serão refeitos, perdendo-se diversas oportunidades vantajosas de ganhos mútuos.

Como a falta de confiança é inevitável, Gulati (1995) propõe tratá-la de forma preventiva, pela avaliação preliminar dos custos envolvidos na estruturação 
da rede em formação e do estabelecimento de um instrumento jurídico que anteveja a ocorrência do comportamento oportunista, tratando-o sob a forma de custos transacionais. Assim, o comportamento oportunista deixa de ser um problema a ser eliminado e passa a ser um aspecto gerenciável, dentro de um contexto de direitos e obrigações entre as partes.

Encarando-se o comportamento oportunista como um custo transacional, previsto e tratado em instrumentos contratuais legais, será mais fácil se estabelecer laços empresariais de longo prazo, com expectativa mais otimista de que ele não ocorra. Assim, o tratamento dado a estas ocorrências deixa de ser o conhecimento e passa a ser a intimidação ou punição, aplicando-se ao integrante de comportamento não confiável, sansões com custos monetários superiores aos eventuais benefícios decorrentes do oportunismo. Uzzi e Gilespie (2002) argumentam que as redes estabelecidas sob o regime de contratos formais ou acordos de equidade, garantem maior intensidade de transferência de conhecimentos e recursos entre os integrantes.

Gulati (1995) argumenta que a confiança é um fenômeno interpessoal, intrínseco às relações sociais, portanto, recorrente no âmbito das redes empresariais, visto serem agrupamentos sociais; a confiança é a expectativa que atenua o temor ao ato oportunista por parte de um parceiro comercial, principalmente quando estão evolvidos fatores relacionados à $\mathrm{P} \& \mathrm{D}$.

Foram avaliadas três redes de cooperação empresarial, em diferentes estágios de formação, a fim de avaliar-se o impacto dos fatores relacionados à $\mathrm{P} \& \mathrm{D}$, ou seja, à inovação tecnológica sobre o fator confiança, conforme descrito a seguir.

\section{Aspectos metodológicos}

Conforme exposto na seção introdutória, o artigo visa levantar os fatores motivadores e críticos ao sucesso da estruturação de redes de cooperação com foco em inovação. Adicionalmente, procura-se explorar o impacto. Para tal, o quadro teórico, composto de 3 blocos conceituais - fatores motivadores, formação da rede e impactos resultantes (Figura 1), foi desdobrado nas seguintes questões de pesquisa:

- atividades de cooperação desenvolvidas pelos integrantes da rede (tais como desenvolvimento de fornecedores, ganhos de escala, logística, marketing, P\&D e utilização conjunta de capacidade produtiva);

- configuração das redes de cooperação em função da natureza dos negócios dos integrantes;

- fatores motivacionais e críticos à cooperação em rede;

- ferramentas de fortalecimento e suporte à implantação de uma rede de cooperação;
- ferramentas de gestão e governança mais frequentes em uma rede de empresas;

- impacto dos resultados da rede sobre os resultados financeiros dos integrantes;

- infraestrutura e recursos de apoio à gestão;

- natureza da governança estabelecida;

- níveis de interação observados entre as empresas integrantes;

- organização da rotina de trabalho da rede social; $\mathrm{e}$

- papéis desempenhados pelos integrantes.

A abordagem metodológica adotada foi a de uma pesquisa de natureza empírica, associada aos objetivos de uma pesquisa exploratória, com dados coletados por meio de abordagem qualitativa e quantitativa. A Figura 3 sintetiza o projeto da pesquisa de campo.

A rede de cooperação empresarial é a unidade de análise que estabelece as fronteiras do objeto de estudo (YIN, 2001). Para seleção das redes de cooperação, utilizamos critérios referentes à consolidação e setor econômico do qual ela faz parte. No critério "consolidação", foram pesquisadas redes de cooperação em diferentes fases de consolidação e no critério "setor econômico" selecionamos redes de empresas de tecnologia (RCE - Empresas Incubadas) e prestadoras de serviços (RCE-Laboratórios Metrológicos e RCE-Química).

$\mathrm{O}$ critério de seleção dos atores atuantes nas redes, para fins de levantamento de dados, foi o seguinte: caso a rede de cooperação tenha uma empresa líder, entrevistar proprietário e/ou diretor; entrevistar proprietário/diretor ou responsável pela atuação junto à rede de cooperação de cada empresa integrante da amostra de empresas participantes da RCE selecionada; caso alguma das redes tenha um gestor da RCE também entrevistá-lo. Todas as redes selecionadas tinham perfil simétrico, sem a figura de empresa líder, porém todas tinham um gestor constituído de modo informal. Todos os gestores foram entrevistados.

A Pesquisa Exploratória foi elaborada em duas etapas; a finalidade da primeira etapa foi avaliar-se a adequação dos instrumentos de pesquisa. Para isto, os questionários foram elaborados conforme o constructo da pesquisa, aplicando-se como teste piloto junto a dois gestores de redes, que responderam tanto aos questionários de gestor quanto de integrante, a fim de avaliar a interpretação e adequação das perguntas. As redes, cujos gestores executaram o teste piloto, foram a REMESP - Rede Metrológica do Estado de São Paulo e a ABRELPE - Associação Brasileira das Empresas de Limpeza Pública e Coleta de Resíduos. Por meio do teste piloto, obtivemos subsídios para a adequação das perguntas aos propósitos da pesquisa. Com isto, avaliamos a facilidade de interpretação do questionário, a clareza dos conceitos pesquisados e verificamos se 

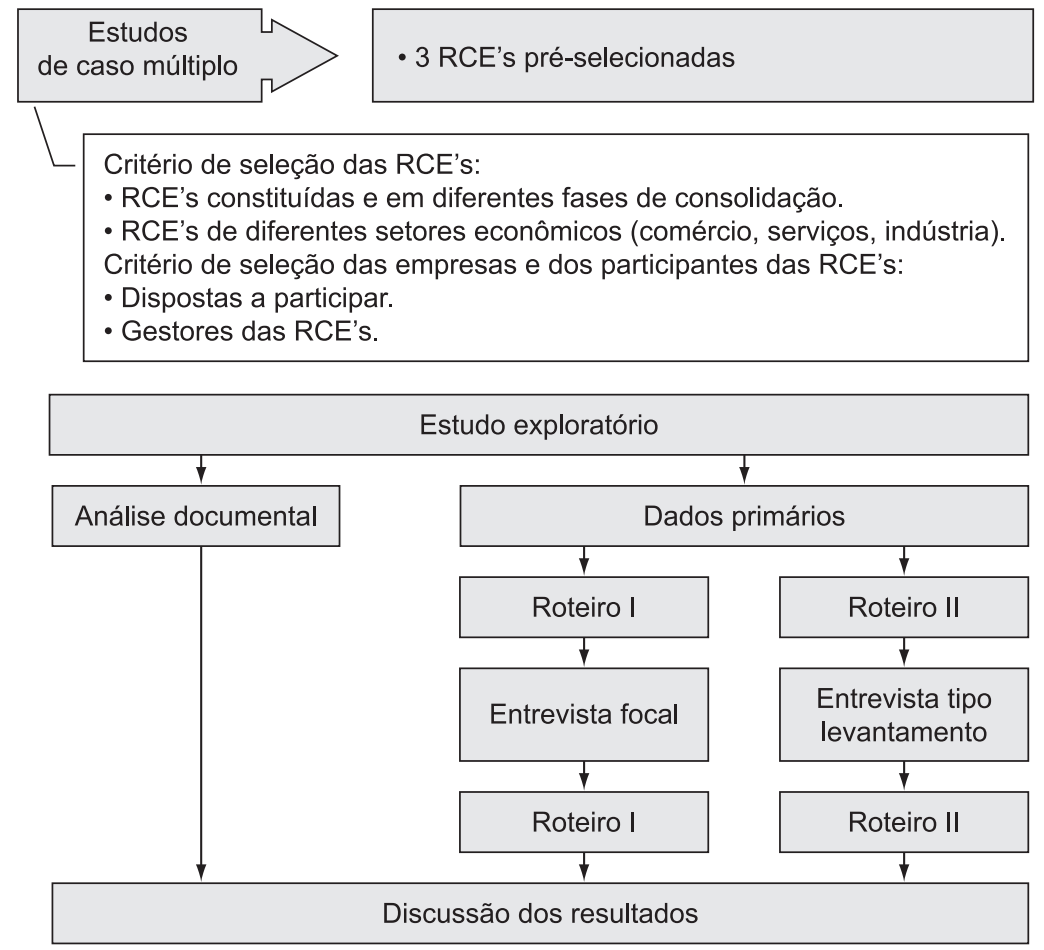

Figura 3. Projeto da pesquisa.

as perguntas estavam dentro do conhecimento e/ou da responsabilidade dos respondentes.

$\mathrm{O}$ instrumento de pesquisa estava em elaboração desde a fase exploratória e por meio do teste piloto, várias perguntas foram remodeladas e algumas alternativas foram acrescentadas, finalizando-se este instrumento sob a forma de questionários de múltipla escolha, dentro da metodologia qualitativa conforme Piovesan e Temporini (1995). Conforme Heyink e Tymstra (1993) a metodologia qualitativa é indicada como método de análise quando um fenômeno está em estágio inicial e busca-se delimitar as fronteiras desse fenômeno; quando há interesse na interpretação dos comportamentos, motivos e emoções dos respondentes; quando o tema da pesquisa envolve situações de impacto para os respondentes; ou quando o objeto de interesse da pesquisa é formado por um conjunto pequeno frente ao universo no qual ele se insere. Como a estruturação de empresas sob a forma de redes de cooperação ainda é incipiente em nosso país, o número de empresas que trabalham sob esta forma de organização das operações ainda é insignificante frente ao universo de empresas; assim, é fundamental a delimitação de suas fronteiras e a avaliação do comportamento dos integrantes.

Os dados quantitativos foram elaborados a partir dos questionários respondidos, tratados estatisticamente de forma descritiva, conforme sugerido por Flynn et al. (1990). O questionário foi aplicado às redes de cooperação de empresas de tecnologia (Incubadores) e prestadoras de serviços (metrologia e química). Apenas os três gestores foram entrevistados, pela entrevista etnográfica, porém, com o apoio do questionário específico dos gestores.

Vale observar que no caso da RCE - Metrológica e RCE - Química, os questionários destinados aos integrantes foram aplicados a proprietários de empresas ou funcionários responsáveis pelos laboratórios, no caso das grandes empresas. Nas entrevistas aplicadas à rede de cooperação das empresas incubadas, foram entrevistados os proprietários das empresas. Esta fase foi realizada em uma única etapa, com a aplicação de quatro a sete questionários em cada rede.

\section{Perfil das redes pesquisadas}

\subsection{Rede de empresas de base tecnológica}

A rede pesquisada situa-se dentro do CIETEC Centro Incubador de Empresas Tecnológicas, incubadora de empresas de tecnologia de ponta, localizada junto ao IPEN - Instituto de Pesquisas Energéticas e Nucleares e USP - Universidade de São Paulo. O próprio centro incubador pode ser caracterizado como uma rede de empresas mais ampla, dentro do qual se situa a rede empresarial analisada. As empresas integrantes desta rede pesquisada apresentam caráter volitivo, hierarquia quase ausente, 
leve assimetria em sua taxonomia e ausência de qualquer amarra jurídica, ou seja, puramente social, composta pelos sete empresários respondentes.

A análise estatística foi elaborada com os resultados dos 7 questionários recebidos de micro empresários, proprietários de empresas incubadas em diferentes estágios, além do questionário aplicado ao gestor, que acumula a função de Responsável por Negócios Internacionais. A Tabela 2 identifica o perfil dos respondentes e da empresa integrante da RCE analisada.

\subsection{Rede de empresas químicas}

A rede de empresas químicas teve sua origem no Comitê de Metrologia criado em 1997, com atuação voltada às atividades de um comitê de metrologia química, restrito ao Estado de São Paulo. Em 1998, o comitê passa a ter abrangência nacional e a partir de 2004 adota a denominação "rede", passando a atuar dentro dos preceitos de uma rede de cooperação em abrangência nacional. Desse modo, seu tempo de existência efetivamente como rede, na ocasião desta pesquisa, era de aproximadamente 50 meses. A indicação de participação média de 72 meses ocorre em função de integrantes agregados ao Comitê original, desde seu estágio inicial.

Esta rede de empresas foi estruturada por demanda da área industrial, com o objetivo de dar suporte tecnológico a seus integrantes. Por sua característica, é fundamentalmente voltada à regulamentação de procedimentos laboratoriais, sem qualquer atividade voltada à comercialização; não há ambiente concorrencial entre os integrantes desta rede. É formada por universidades públicas e privadas, institutos de pesquisa, redes metrológicas químicas, empresas públicas e privadas, órgãos de controle ambiental e comitês de metrologia, tais como: USP, Universidade Mackenzie, IPT,

Tabela 2. Caracterização da empresa incubada e do respondente.

\begin{tabular}{|c|c|c|c|}
\hline Empresa & Área & $\begin{array}{c}N^{o} \text {. de } \\
\text { funcionários }\end{array}$ & $\begin{array}{c}\text { Escolaridade } \\
\text { do } \\
\text { empresário }\end{array}$ \\
\hline 1 & TI & 3 & Colegial \\
\hline 2 & TI & 8 & Superior \\
\hline 3 & TI & 5 & Superior \\
\hline 4 & Mecânica & 14 & Superior \\
\hline 5 & $\mathrm{TI}$ & 2 & $\begin{array}{l}\text { Superior } \\
\text { Incompleto }\end{array}$ \\
\hline 6 & TI & 4 & $\begin{array}{c}\text { Pós- } \\
\text { graduação }\end{array}$ \\
\hline 7 & Biotecnologia & 2 & Superior \\
\hline
\end{tabular}

Fonte: Elaborada pelos autores.
RMRS - Rede Metrológica do Rio Grande do Sul, Petrobrás, INMETRO, Oxiteno e CETESB, integrando 37 organizações e 130 integrantes de 12 estados e Distrito Federal. Desde que a rede se originou do Comitê de Metrologia Química, atua em programas de âmbito nacional com o objetivo de instituir o conceito de metrologia química e apoiar a melhoria das medições. Dentre seus objetivos principais está a definição de processos de análise e medição química, divulgação de normas e procedimentos técnicos aos associados e elaboração de normas junto à ABNT.

A análise estatística foi elaborada com os resultados de 4 questionários recebidos do representante de um Serviço de Aprendizagem da Bahia, de 2 representantes de um instituto de pesquisas em energia e de uma bolsista de um Programa de Medições de São Paulo. Os tempos individuais de participação são bastante dispersos, variando entre 2 e 10 anos, com duração média de 72 meses e com desvio padrão de 43,82.

\subsection{Rede de empresas metrológicas}

Esta RCE é formada por consultores independentes, laboratórios metrológicos públicos e privados, empresas estatais e privadas, instituições de ensino e pesquisa e órgãos públicos de normatização e padronização, totalizando 150 integrantes. Foi criada por empresários em agosto de 1998, para integrar uma rede de laboratórios metrológicos, a fim de promoverem ações voltadas ao grupo. Sua sustentação econômica ocorre por meio da contribuição de associados e de recursos provenientes de órgãos públicos e privados, tais como IPT, SENAI-SP e SEBRAE, entre outros. A atividade principal dos integrantes desta rede é a prestação de serviços de calibração e aferição de instrumentos e equipamentos industriais, a fim de proporcionar confiabilidade aos processos de execução e controle.

De acordo com o procedimento metodológico, foi estabelecido o contato pessoal com o Gestor da Rede para aplicação do questionário de pesquisa, junto à entrevista focal, enquanto os questionários dos integrantes da RCE foram encaminhados pela Internet. A amostra das empresas integrantes da pesquisa incluiu um Centro de Metrologia Industrial, um Laboratório prestador de serviços de Metrologia à indústria, uma Consultora independente em qualidade metrológica associada à rede de cooperação e o Laboratório de Metrologia de uma das maiores multinacionais da área de ferramentas de corte. Os respondentes, à exceção da consultora que atua de forma independente, eram os responsáveis pelos laboratórios metrológicos.

\section{Discussão dos resultados}

Por meio dos dados coletados em cada uma das RCE participantes, foi construída a síntese analítica, com resultados e conclusões preliminares. O tempo 
de compartilhamento tem relação direta com a quantidade de atividades compartilhadas; redes mais antigas apresentam maior compartilhamento de atividades, conforme observado na Tabela 3. Esta característica se aplica aos integrantes de cada rede: integrantes mais antigos compartilham mais atividades. Observou-se também que os profissionais que integram a rede sob a forma de representantes de entidades ou funcionários de empresas, apresentam melhor resposta ao compartilhamento que os proprietários das empresas integrantes. Este dado pode estar relacionado tanto à concentração do empresário em atividades específicas de sua empresa (faturamento, recolhimento de impostos, etc.), como por fatores relacionados à confiança e motivação.

O tipo de atividade compartilhada está relacionado diretamente aos interesses fundamentais do grupo. Enquanto as empresas incubadas buscam identificação e reconhecimento de seu mercado, pela publicidade conjunta, a rede de empresas químicas busca subsídios para sua atuação, enquanto a rede de laboratórios metrológicos busca o atendimento aos clientes (direta e indiretamente, pela condenação de práticas ilegais), fonte de seus recursos financeiros.

Os dados acima confirmam o amadurecimento da rede de cooperação como aspecto fundamental à visualização de atividades potencialmente agregadoras de valor, mesmo que ainda não compartilhadas.

As atividades não compartilhadas, mas passíveis de o serem, confirmam a convergência ao objetivo comum do grupo. Empresas incubadas buscam seu posicionamento no mercado por meio de feiras, exposições e trocas horizontais; empresas químicas objetivam redução de custos para subsidiar tecnologicamente seus integrantes; empresas de metrologia buscam redução de custos de atuação, a fim de melhorar sua competitividade frente ao mercado em que atuam.
As atividades “jamais compartilháveis” confirmam as conclusões sobre amadurecimento da rede; redes mais "jovens" apresentam maior resistência ao compartilhamento e esta resistência se reduz conforme aumenta o tempo de existência da rede. As atividades "jamais compartilháveis" remetem ao objetivo comum do grupo e já indicam sinais de temor ao comportamento oportunista, conforme indicado na Tabela 4.

Para os integrantes da rede de empresas incubadas, essas atividades (aquisição e desenvolvimento conjunto de produtos e insumos) estão claramente relacionadas ao temor quanto ao compartilhamento da tecnologia em desenvolvimento. Na rede de laboratórios de metrologia, a atividade jamais compartilhável mais citada, está associada diretamente aos clientes, a fonte de recursos financeiros da empresa.

As atividades indicadas como "não citadas" não sofreram qualquer tipo de indicação, seja como "passiveis de compartilhamento" ou como "jamais compartilháveis", indicando desconhecimento de seu potencial, positivo ou negativo, novamente associado ao amadurecimento da rede de cooperação.

Os resultados referentes ao fornecimento ou recebimento de informações estratégicas confirmam as afirmações de Gulati (1995). As empresas de base tecnológica apresentam elevada restrição ao fornecimento de informações estratégicas, na mesma proporção em que afirmam não receber informações estratégicas, dado relacionado à natureza de suas atividades, de pesquisa e desenvolvimento de novas tecnologias. Os laboratórios metrológicos, fortemente dependentes dos resultados financeiros de seus mercados, são ainda mais intensivos neste aspecto; a certeza quanto a não fornecer ou não receber informações estratégicas é quase absoluta. No caso das empresas químicas, observamos um resultado coerente com o observado nas outras redes; como se

Tabela 3. Análise cruzada das redes.

\begin{tabular}{|c|c|c|c|}
\hline \multirow[t]{2}{*}{ Pergunta } & \multicolumn{3}{|c|}{ Tipo da RCE (quantidade) } \\
\hline & $\begin{array}{c}\text { Empresas de base } \\
\text { tecnológica }(7)\end{array}$ & $\begin{array}{c}\text { Empresas } \\
\text { químicas (4) }\end{array}$ & $\begin{array}{c}\text { Laboratórios } \\
\text { metrológicos (4) }\end{array}$ \\
\hline $\begin{array}{l}\text { Há quanto tempo você participa da } \\
\text { estrutura de cooperação? }\end{array}$ & 20,5 meses & 72 meses & 72 meses \\
\hline $\begin{array}{l}\text { Percentual de atividades } \\
\text { compartilhadas }\end{array}$ & $8,16 \%$ & $18,57 \%$ & $24,29 \%$ \\
\hline $\begin{array}{l}\text { Que tipo de atividade você } \\
\text { compartilha? }\end{array}$ & $\begin{array}{c}\text { Publicidade e } \\
\text { propaganda } \\
\text { conjunta }(30 \%)\end{array}$ & $\begin{array}{c}\text { Desenvolvimento } \\
\text { conjunto de } \\
\text { componentes, } \\
\text { produtos e fornecedores } \\
(30,8 \%)\end{array}$ & $\begin{array}{l}\text { Promoção junto ao } \\
\text { mercado para divulgação } \\
\text { da importância e combate } \\
\text { a práticas ilegais (12\%) } \\
\text { Atendimento a clientes e } \\
\text { assistência técnica (12\%) }\end{array}$ \\
\hline $\begin{array}{l}\text { Média de atividades compartilhadas, } \\
\text { por integrante }\end{array}$ & 5 & 6,5 & 8,5 \\
\hline
\end{tabular}


Tabela 4. Atividades ainda não compartilhadas e atividades jamais compartilháveis.

\begin{tabular}{|c|c|c|c|}
\hline \multirow[t]{2}{*}{ Pergunta } & \multicolumn{3}{|c|}{ Tipo da RCE (quantidade) } \\
\hline & $\begin{array}{l}\text { Empresas de base } \\
\text { tecnológica }(7)\end{array}$ & $\begin{array}{c}\text { Empresas } \\
\text { químicas (4) }\end{array}$ & $\begin{array}{c}\text { Laboratórios } \\
\text { metrológicos (4) }\end{array}$ \\
\hline $\begin{array}{l}\text { Percentual de atividades ainda não } \\
\text { compartilhadas, mas gostaria de } \\
\text { compartilhar. }\end{array}$ & $27,78 \%$ & $40,28 \%$ & $57,64 \%$ \\
\hline \multirow{2}{*}{$\begin{array}{l}\text { Que tipo de atividade você não } \\
\text { compartilha, mas gostaria de } \\
\text { compartilhar? }\end{array}$} & $\begin{array}{l}\text { Participação conjunta em } \\
\text { feiras e exposições }(7,1 \%)\end{array}$ & $\begin{array}{l}\text { Redução de custos } \\
\qquad(6,9 \%)\end{array}$ & \multirow{2}{*}{$\begin{array}{l}\text { Importações conjuntas } \\
\text { de insumos básicos, } \\
\text { semiacabados e bens } \\
\text { de capital }(9,6 \%)\end{array}$} \\
\hline & $\begin{array}{l}\text { Vendas aos demais } \\
\text { integrantes da rede de } \\
\text { cooperação }(7,1 \%)\end{array}$ & & \\
\hline $\begin{array}{l}\text { Percentual de atividades que você } \\
\text { jamais compartilharia. }\end{array}$ & $13,49 \%$ & $6,25 \%$ & $4,86 \%$ \\
\hline \multirow[t]{2}{*}{$\begin{array}{l}\text { Que tipo de atividade você jamais } \\
\text { compartilharia? }\end{array}$} & $\begin{array}{l}\text { Aquisição conjunta de bens e } \\
\text { insumos }(17,65 \%)\end{array}$ & $\begin{array}{l}\text { Compartilhamento de } \\
\text { mão de obra }(22,2 \%)\end{array}$ & $\begin{array}{l}\text { Atendimento a } \\
\text { clientes }(28,57 \%)\end{array}$ \\
\hline & $\begin{array}{l}\text { Desenvolvimento conjunto } \\
\text { de produtos, componentes e } \\
\text { processos }(17,65 \%)\end{array}$ & $\begin{array}{l}\text { Atendimento a } \\
\text { clientes }(22,2 \%)\end{array}$ & \\
\hline Atividades não citadas & $50,79 \%$ & $35,42 \%$ & $13,89 \%$ \\
\hline
\end{tabular}

Fonte: Elaborada pelos autores.

trata de uma rede de cooperação voltada à circulação de informações, subsídios aos integrantes e elaboração de normas junto à $\mathrm{ABNT}$, com reduzido índice de atividades comerciais, o grau de certeza quanto ao recebimento e fornecimento de informações estratégicas é elevado;

A indicação das informações não compartilháveis novamente associa o temor ao comportamento oportunista à atividade principal dos integrantes. Enquanto a rede de empresas de base tecnológica não fornece dados referentes à tecnologia de processos, a rede de laboratórios metrológicos não fornece dados referentes à margem de lucros, informação básica ao estabelecimento de preços, dado fundamental à concorrência de mercado. Este resultado adere à forma de circulação de informações: quando ela ocorre, prevalece o modo informal de circulação ao mesmo tempo em que os percentuais referentes a não circulação de informações são significativos, o que demonstra o temor ao comportamento oportunista.

Enquanto na rede de empresas químicas, nenhum integrante apontou a ocorrência de "não circulação", dada sua natureza de apoio tecnológico, o dado ocorre na rede de empresas de base tecnológica e, com mais intensidade, nas empresas de serviços metrológicos. Os números confirmam os dados correspondentes aos graus de restrição observados entre os integrantes das redes; quanto menor a troca de informações, maiores as reservas em relação aos parceiros da rede. Enquanto isso, o temor ao comportamento oportunista está presente em todas as redes, conforme indicado na Tabela 5, mesmo na rede química na qual há pequena presença de concorrência entre os participantes.
Os gestores e os integrantes das redes foram informados quanto às diferentes taxonomias das formas de cooperação para, em seguida, classificarem as redes às quais estão integrados.

A rede de empresas incubadas foi autoclassificada como levemente assimétrica devido à atuação do gestor, cuja atuação está limitada às decisões dos integrantes; porém, analisando-se seu perfil sob os conceitos discutidos anteriormente, sua formação é tipicamente social e de perfil sinérgico, mesmo havendo temor ao comportamento oportunista. Este fato pode estar associado ao caráter mais motivacional do que volitivo de seus integrantes, visto que, a adesão ou a saída da rede é totalmente livre, sem amarras jurídicas.

A rede de empresas químicas, apesar de contar com uma diretoria constituída atuando como canal pré-definido para circulação das informações, apresenta leve assimetria e perfil sinérgico, em função de sua atividade voltada essencialmente à capacitação dos integrantes.

A rede de empresas metrológicas tem um corpo diretivo constituído formalmente por assembleias, com mandatos definidos, estatutos registrados, adesão formal dos integrantes e tomadas de decisões formalizadas em assembleias programadas. Estes dados, combinados ao caráter comercial e técnico da rede, tornam seu perfil tipicamente assimétrico.

O modo como a informação flui e o tipo de força atuante entre os integrantes das redes estabelece a taxonomia das redes pesquisadas quanto ao seu aprendizado, caracterizando-as como evolucionárias e retrátil-reversíveis, conforme indicado na Tabela 6 . 
Tabela 5. Fluxo de informações e confiança mútua.

\begin{tabular}{|c|c|c|c|}
\hline \multirow[t]{2}{*}{ Pergunta } & \multicolumn{3}{|c|}{ Tipo da RCE (quantidade) } \\
\hline & $\begin{array}{l}\text { Empresas de base } \\
\text { tecnológica }(7)\end{array}$ & $\begin{array}{c}\text { Empresas } \\
\text { químicas (4) }\end{array}$ & $\begin{array}{c}\text { Laboratórios } \\
\text { metrológicos (4) }\end{array}$ \\
\hline Fornece informações estratégicas? & Não $(57,14 \%)$ & Não $(25 \%)$ & Não $(75 \%)$ \\
\hline Recebe informações estratégicas? & Não $(57,14 \%)$ & Não $(25 \%)$ & Não $(75 \%)$ \\
\hline $\begin{array}{l}\text { Que tipo de informação você não } \\
\text { compartilha? }\end{array}$ & $\begin{array}{l}\text { Tecnologia de processo } \\
\text { de produção }(16,67 \%)\end{array}$ & $\begin{array}{l}\text { Faturamento } \\
\quad(28,6 \%)\end{array}$ & $\begin{array}{l}\text { Margem de lucro } \\
\quad(19,05 \%)\end{array}$ \\
\hline \multirow{3}{*}{$\begin{array}{l}\text { Forma predominante de circulação } \\
\text { da informação. }\end{array}$} & Informal $(50 \%)$ & Informal $(55,5 \%)$ & Informal (20\%) \\
\hline & Formal $(37,5 \%)$ & Formal $(44,5 \%)$ & Formal $(20 \%)$ \\
\hline & $\begin{array}{c}\text { Não há troca de } \\
\text { informações }(12,5 \%)\end{array}$ & $\begin{array}{l}\text { Não há troca de } \\
\text { informações }(0 \%)\end{array}$ & $\begin{array}{l}\text { Não há troca de } \\
\text { informações }(60 \%)\end{array}$ \\
\hline $\begin{array}{l}\text { No processo de troca de } \\
\text { informações entre os integrantes } \\
\text { da rede, você identifica: }\end{array}$ & $\begin{array}{l}\text { Confiança pontual ou } \\
\text { apenas entre alguns } \\
\text { integrantes }(57,2 \%)\end{array}$ & $\begin{array}{l}\text { Grau satisfatório de } \\
\text { confiança }(75 \%)\end{array}$ & $\begin{array}{l}\text { De certa restrição à } \\
\text { restrição total entre os } \\
\text { participantes }(75 \%)\end{array}$ \\
\hline \multirow[t]{3}{*}{$\begin{array}{l}\text { No processo de troca de } \\
\text { informações entre os integrantes } \\
\text { da rede, você: }\end{array}$} & $\begin{array}{c}\text { Tem reservas em relação } \\
\text { a alguns integrantes } \\
(57,14 \%)\end{array}$ & $\begin{array}{c}\text { Entre reservas a } \\
\text { significativas reservas } \\
(75 \%)\end{array}$ & $\begin{array}{c}\text { Entre reservas a } \\
\text { significativas reservas } \\
(75 \%)\end{array}$ \\
\hline & & & $\begin{array}{l}\text { Não compartilha } \\
\text { informações; prevalece } \\
\text { o sigilo }(25 \%)\end{array}$ \\
\hline & $\begin{array}{l}\text { Confia plenamente em } \\
\quad \text { todos }(42,86 \%)\end{array}$ & $\begin{array}{l}\text { Confia plenamente em } \\
\text { todos }(25 \%)\end{array}$ & $\begin{array}{c}\text { Confia plenamente em } \\
\text { todos }(0 \%)\end{array}$ \\
\hline $\begin{array}{l}\text { Maior temor relativo ao } \\
\text { parceiro da RCE }\end{array}$ & $\begin{array}{c}\text { Comportamento } \\
\text { oportunista }(46,2 \%)\end{array}$ & $\begin{array}{c}\text { Comportamento } \\
\text { oportunista }(50,0 \%)\end{array}$ & $\begin{array}{c}\text { Comportamento } \\
\text { oportunista }(50,0 \%)\end{array}$ \\
\hline
\end{tabular}

Fonte: Elaborada pelos autores.

Tabela 6. Taxonomias observadas nas redes.

\begin{tabular}{lccc}
\hline \multicolumn{1}{c}{ Pergunta } & \multicolumn{3}{c}{ Tipo da RCE (quantidade) } \\
\cline { 2 - 4 } & $\begin{array}{c}\text { Empresas de base } \\
\text { tecnológica (7) }\end{array}$ & $\begin{array}{c}\text { Empresas } \\
\text { químicas (4) }\end{array}$ & $\begin{array}{c}\text { Laboratórios } \\
\text { metrológicos (4) }\end{array}$ \\
\hline $\begin{array}{l}\text { Hierarquia (avaliação da } \\
\text { simetria da rede) }\end{array}$ & $\begin{array}{c}\text { Levemente assimétrica a } \\
\text { assimétrica }(90 \%)\end{array}$ & $\begin{array}{c}\text { Levemente assimétrica a } \\
\text { assimétrica (75\%) }\end{array}$ & $\begin{array}{c}\text { Assimétrica } \\
(100 \%)\end{array}$ \\
Formalização & Social assimétrica & Burocrática simétrica & Burocrática assimétrica \\
Força atuante & $(100 \%)$ & $(100 \%)$ & $(100 \%)$ \\
Troca de informações com & Sinergia $(83,33 \%)$ & Sinergia (100\%) & Nivelamento $(66,67 \%)$ \\
mercado & Coletivamente & Individualmente & Há pouca interferência \\
Tipologia quanto à interação e & $(41,67 \%)$ & $(50 \%)$ & com o mercado (50\%) \\
aprendizado & Evolucionária & Evolucionária & Retrátil-reversível
\end{tabular}

Fonte: Elaborada pelos autores.

Apesar das redes de empresas de base tecnológica e de empresas químicas terem sido classificadas como simétricas, portanto, geridas pelos próprios integrantes, constatou-se que a presença do gestor é considerada estratégica e satisfatória pela maioria dos integrantes, mesmo quando não há total satisfação com o fluxo do conhecimento e com o tipo de compartilhamento observado na rede, conforme Tabela 7.

Apesar dos aspectos apontados, principalmente a presença do temor ao comportamento oportunista ou baixo índice de circulação de informações, a integração à rede é considerada satisfatória pela maioria dos integrantes, conforme a Tabela 8.

A rede de empresas químicas apontou não expansão nos negócios e não evolução do faturamento em função de seu perfil, suporte tecnológico aos integrantes, não associado à atividade comercial. Por outro lado, a atividade comercial é preponderante nas redes de empresas de base tecnológica e de laboratórios metrológicos.

A Tabela 9 sintetiza as taxonomias observadas nas redes pesquisadas. 
Tabela 7. Satisfação com a atuação do gestor da rede.

\begin{tabular}{|c|c|c|c|}
\hline \multirow[t]{2}{*}{ Pergunta } & \multicolumn{3}{|c|}{ Tipo da RCE (quantidade) } \\
\hline & $\begin{array}{c}\text { Empresas de base } \\
\text { tecnológica }(7)\end{array}$ & $\begin{array}{c}\text { Empresas } \\
\text { químicas (4) }\end{array}$ & $\begin{array}{c}\text { Laboratórios } \\
\text { metrológicos (4) }\end{array}$ \\
\hline Atuação do gestor & Estratégica (100\%) & Estratégica (80\%) & Estratégica (100\%) \\
\hline $\begin{array}{l}\text { Atividades desempenhadas } \\
\text { pelo gestor }\end{array}$ & $\begin{array}{l}\text { Aprimoramento da } \\
\text { qualidade }(10,34 \%)\end{array}$ & $\begin{array}{l}\text { Oportunidades comerciais/ } \\
\text { fontes de financiamento/ } \\
\text { atração de invest. }(28,6 \%)\end{array}$ & $\begin{array}{c}\text { Basicamente } \\
\text { área comercial: } \\
\text { financiamentos, } \\
\text { mercado, etc. }(33,33 \%)\end{array}$ \\
\hline Satisfação em relação ao gestor & $\operatorname{Sim}(71,14 \%)$ & $\operatorname{Sim}(100 \%)$ & $\operatorname{Sim}(50 \%)$ \\
\hline
\end{tabular}

Fonte: Elaborada pelos autores.

Tabela 8. Grau de satisfação quanto ao desempenho dos negócios.

\begin{tabular}{lccc}
\hline \multicolumn{1}{c}{ Pergunta } & \multicolumn{3}{c}{ Tipo da RCE (quantidade) } \\
\cline { 2 - 4 } & $\begin{array}{c}\text { Empresas de base } \\
\text { tecnológica (7) }\end{array}$ & $\begin{array}{c}\text { Empresas } \\
\text { químicas (4) }\end{array}$ & $\begin{array}{c}\text { Laboratórios } \\
\text { metrológicos (4) }\end{array}$ \\
\hline Evolução do faturamento & $62,50 \%$ & Não indicado & Apenas 1 declarou (20\%) \\
Expansão dos negócios & Sim (100\%) & Não (66,67\%) & Sim (75\%) \\
Resultados positivos adicionais & Sim (100\%) & Sim (75\%) & Sim (50\%) \\
Satisfação em participar da RCE & Parcialmente (57,14\%) & Sim (100\%) & Sim (50\%) \\
\hline
\end{tabular}

Fonte: Elaborada pelos autores.

Tabela 9. Perfil das redes analisadas.

\begin{tabular}{lccc}
\hline \multicolumn{1}{c}{ Característica } & $\begin{array}{c}\text { Empresas de base } \\
\text { tecnológica }\end{array}$ & $\begin{array}{c}\text { Rede de Cooperação } \\
\text { químicas }\end{array}$ & $\begin{array}{c}\text { Empresas de } \\
\text { metrologia }\end{array}$ \\
\hline Grau de Hierarquia & $\begin{array}{c}\text { Levemente Assimétrica } \\
\text { com Coordenação }\end{array}$ & $\begin{array}{c}\text { Levemente Assimétrica } \\
\text { com Coordenação }\end{array}$ & $\begin{array}{c}\text { Assimétrica com } \\
\text { Empresa Líder } \\
\text { Formalização legal }\end{array}$ \\
Social Simétrica & Social Assimétrica & Burocrática Assimétrica \\
Cooperação & Horizontal & Horizontal/Vertical & Vertical \\
Característica dos & Fracos & Fracos & Ausentes \\
laços predominantes & Interativos e & Associativistas e & Associativistas e \\
Classificação dos laços & Transferenciais & Transferenciais & Formais \\
predominantes & Evolucionária & Evolucionária & Retrátil-reversível \\
Categoria da rede & Sinergia & Sinergia & Nivelamento \\
Forças atuantes & Alta incidência & Média incidência & Baixa incidência \\
Buracos estruturais & &
\end{tabular}

Fonte: Elaborada pelos autores.

\section{Conclusão}

Ao analisarmos as RCEs descritas, constatou-se que o fator motivador à formação das redes é a possibilidade de expansão dos negócios associado ao potencial de compartilhamento de atividades.

O fator crítico fundamental é o temor ao comportamento oportunista, que foi apontado por aproximadamente metade dos entrevistados, nas três redes estudadas. Em especial, este aspecto foi o fator limitante à formação da rede com as empresas de base tecnológica, objeto da pesquisa ação, o que confirma a abordagem de Olave e Amato Neto (2001) sobre Cultura da Confiança. Entretanto, revendo-se Gulati (1995), trata-se de um fator presente em todas as redes empresariais, demandando procedimentos legais adequados. Não é conveniente estabelecer-se o sucesso na estruturação de uma RCE à incorporação e estímulo aos laços fortes, limitantes à troca de informações. $\mathrm{O}$ fator confiança deve ser tratado como um custo operacional e incorporado aos instrumentos legais estabelecidos pelo grupo. Conforme Gulati (1995), quando há ocorrência de atividades de P\&D, ou seja, quando o 
conhecimento for uma commodity dentro de uma RCE, é conveniente que os vínculos empresariais sejam estabelecidos na forma de participações acionárias equilibradas ou igualitárias, que facilitem o acordo entre as partes e possibilitem diluição equilibrada dos custos transacionais decorrentes do oportunismo. $\mathrm{Na}$ pesquisa, observou-se que nas redes burocráticas (ver Tabela 6 e 8) a satisfação é plena, enquanto que nas redes de empresas de base tecnológica a satisfação é parcial, apesar do reconhecimento dos impactos positivos no negócio.

Um dado importante, portanto, refere-se ao estabelecimento de instrumentos jurídicos adequados que desmotivem o comportamento oportunista. Porém, caberá aos integrantes da rede a adoção de instrumentos adequados, sem uma formalização excessiva que possa impedir a evolução da rede ou o bloqueio de seu fluxo de informação. Deve-se preservar o caráter sinérgico e o aprendizado criativo.

O tempo de amadurecimento de uma rede de cooperação empresarial é outro fator crítico ao sucesso do compartilhamento. Na pesquisa, observou-se que o número de atividades compartilhadas evolui em função do tempo de ingresso na rede (ver Tabela 3 ). Ao longo do tempo, os integrantes identificam novas oportunidades de compartilhamento ao mesmo tempo que estabelecem laços fracos, fundamentais ao fluxo da informação e conhecimento. O tempo de amadurecimento necessário à rede implica em poucos resultados imediatos e o cumprimento do amadurecimento da rede é viabilizado em função do caráter motivacional dos integrantes. É neste aspecto que o caráter volitivo pode comprometer os resultados esperados, pois a adesão voluntária pode criar uma expectativa de resultados mais imediatos, gerando frustração e desmotivação devido à perspectiva de médio ou longo prazo necessária para o surgimento dos primeiros resultados, conforme Tálamo (2009).

Outra conclusão importante refere-se à presença do gestor. Em todas as redes estudadas a figura do gestor é estratégica e há satisfação com sua atuação, embora os papéis assumidos divirjam de acordo com a configuração das redes (ver Tabelas 6 e 7). As redes simétricas e flexíveis apresentam uma taxonomia favorável ao sucesso da cooperação justamente por não apresentarem qualquer amarra jurídica ou traço de hierarquia. Entretanto, a figura do gestor (broker) da rede é um aspecto crítico ao sucesso; sua presença pode estabelecer uma hierarquia operacional que prioriza as necessidades da operação, sem que ocorra perda de identidade das empresas integrantes.

\section{Referências}

AMATO NETO, J. Redes de cooperação produtiva e clusters regionais: oportunidades para as pequenas e médias empresas. São Paulo: Atlas, 2000.
BELUSSI, F.; ARCANGELI, F. A typology of networks: flexible and evolutionary firms. Research Policy, v. 27, p. 415-428, 1998.

BORGATTI, S. P.; CROOS, R. A relational view of information seeking and learning in social networks. Management Science, Evanston, v. 49, n. 4, p. 432-445, 2003. Disponível em: <http://mansci.journal.informs. org >. Acesso em: 19 jul. 2007.

CARVALHO, M. M. Inovação: estratégia e comunidades de conhecimento. São Paulo: Ed. Atlas, 2009.

CARVALHO, M. M.; SERRA, N.; LAURINDO, F. J. B. Strategic choices in Brazilian textile \& apparel industries. In: EUROPEAN OPERATIONS MANAGEMENT ASSOCIATION \& PRODUCTION AND OPERATIONS MANAGEMENT SOCIETY FIRST JOINT INTERNATIONAL CONFERENCE - EUROMA\&POMS2003, 2003., Cernobbio. Proceedings... 2003, v. 1, p. 219-228.

CHESBROUGH, H. W.; APPLEYARD, M. M. Open Innovation and Strategy. California Management Review, v. 50, n. 1, p. 57-77, 2007. Disponível em: <http://media. web.britannica.com/ebsco/pdf/265/27340265.pdf>. Acesso em: ago. 2007.

FLYNN, B. B. et al. Empirical research methods in operations management. Journal of Operations Management, v. 9, n. 2, p. 250-284, 1990. Disponível em: <www. sciencedirect.com/science>. Acesso em: jun. 2007.

FUSCO, J. P. A. et al. Redes produtivas e cadeias de fornecimento. São Paulo: Arte \& Ciência, 2005.

GRANOVETTER, M. Economic action and social structure: the problem of embeddedness. American Journal of Sociology, v. 91, p. 481, 1985. Disponível em: <http:// www.journals.uchicago.edu>. Acesso em: 15 jul. 2007.

GULATI, R. Does familiarity breed trust? The implications of repeated ties for contractual choice in alliances. Academy of Management Journal, v. 38, n. 1, p. 85-112, 1995. Disponivel em: <http://proquest.umi.com/pqd > Acesso em: jan. 2008.

HEYINK, J. W.; TYMSTRA, T. J. The function of qualitative research. Social Indicators Research, v. 29, p. 291-305, 1993. Disponível em: <www.springerlink.com/content/ g22521v090775613>. Acesso em: dez. 2007.

KARLSSON, C. The development of industrial networks challenges to operations management in an extraprise. International Journal of Operations \& Production Management, v. 23, n. 1, p. 44-61, 2003. Disponível em: <www.emeraldinsight.com/researchregister>. Acesso em: 19 ago. 2006.

LAZZARINI, S. G., CHADDAD, F. R.; NEVES, M. F. O Conceito de capital social e aplicações para desenvolvimento e estratégia sustentável. Pesquisa Agrícola, p. 10-14, 2000. Disponível em: <http:// pa.esalq.usp.br/ pa/pa0500/serg0500.pdf >. Acesso em: 13 jun. 2007.

LOEBBECKE C.; VAN FENEMA P. Towards a theory of inter-organizational knowledge sharing during co-opetition. In: EUROPEAN CONFERENCE ON IS, AIX-EN-PROVENCE, 1998. Proceedings...

MALAFAIA, G. C. et al. capital social e a construção da confiança em redes de cooperação: mudando padrões de relacionamento na pecuária de corte. In: ENCONTRO 
DA ANPAD, 31., 2007. Anais... Rio de Janeiro: ANPAD, 2007.

MATHEUS, R. F.; SILVA, A. B. O. Análise de redes sociais como método para a Ciência da Informação. Revista de Ciência da Informação, v. 7, n. 2, 2006. Disponível em: <www.eprints.rclis.org/archive/00006190/01/Art_03. htm\#autor2>. Acesso em: jun. 2007.

OLAVE, M. E. L.; AMATO NETO, J. Redes de cooperação produtiva: uma estratégia de competitividade e sobrevivência para pequenas e médias empresas. Gestão \& Produção, São Carlos, v. 8, n. 3, p. 289-303, 2001. ONYX, J.; BULLEN, P. Measuring social capital in five communities. Journal of Applied Behavioral Science, v. 36, p. 23, 2000. Disponível em: <http://proquest.umi. com/pqdweb?index>. Acesso em: fev. 2008.

PIOVESAN, A.; TEMPORINI, E. R. Pesquisa exploratória: procedimento metodológico para o estudo de fatores humanos no campo da saúde pública. Revista da Saúde Pública, v. 29, n. 4, p. 318-325, 1995. Disponível em: $<$ http://www.scielo.br/pdf/rsp/v29n4/10.pdf > . Acesso em: dez. 2006.

PRAHALAD, C. K.; RAMASWAMY, V. Co-creation experiences: The next practice in value creation. Journal of Interactive Marketing. v. 18, n. 3, p. 5-14, 2004.
STOKES, D. E. O quadrante de Pasteur: a ciência básica e a inovação tecnológica. Campinas: Unicamp, 2005.

STORPER, M.; HARRISON, B. Flexibility, hierarchy and regional developments: the changing structure of industrial production systems and their forms of governance in the 1990s. Research Policy, v. 20, n. 5, 1991.

TÁLAMO, J. R. Formação e gestão de redes de cooperação empresarial. 2008. 233 f. Tese (Doutorado em Engenharia de Produção)-Escola Politécnica, Universidade de São Paulo, São Paulo, 2008.

TÁLAMO, J. R. Redes empresariais: um estudo dos fatores motivacionais e inibidores. SIMPÓSIO DE ENGENHARIA DE PRODUÇÃO - SIMPEP, 16. 2009, Bauru. Anais...

UZZI, B.; GILESPIE, J. J. Knowledge spillover in corporate financing networks: embeddedness and the firm's performance. Strategic Managemente Journal, v. 23, p. 595-618, 2002. Disponível em: <www3.interscience. wiley.com/cgi-bin/fulltext/92013619/PDFSTART>. Acesso em: dez. 2008.

YIN, R. K. Estudo de caso: planejamento e métodos. 2. ed. Porto Alegre: Bookman, 2001. 